\title{
Genomic Organization of the FMRFamide Gene in Lymnaea: Multiple Exons Encoding Novel Neuropeptides
}

\author{
Elaine Kellett,' Susan E. Saunders, ${ }^{1}$ Ka Wan Li, ${ }^{2}$ Julian W. Staddon, ${ }^{1}$ Paul R. Benjamin, ${ }^{1}$ and Julian F. Burke ${ }^{1}$ \\ 'Sussex Centre for Neuroscience, University of Sussex, Brighton, BN1 9QG, United Kingdom and ${ }^{2}$ Graduate School of \\ Neurosciences, Vrije Universiteit, Faculty of Biology, Amsterdam, Netherlands
}

\begin{abstract}
Based on the sequencing of genomic and cDNA clones, we were able to determine that the FMRFamide gene consists of five exons covering at least $20 \mathrm{~kb}$ and predict the presence of further novel peptides. The exons are alternatively spliced: exon I (hydrophobic leader sequence) to exon II (tetrapeptides) and exon I to exons III (heptapeptides), IV, and $V$. A cDNA clone encoding the heptapeptides is described and has also been shown to encode further novel peptides SKPYMRFamide, HDYMRFamide, and SSFPRYamide. Analysis of the right internal parietal nerve using mass spectrometry showed that the novel peptide SKPYMRFamide was cleaved from the precursor. This peptide excites neurons, suggesting a physiological function in the CNS.

IKey words: Lymnaea, FMRFamide, genomic organization, alternative splicing, neuropeptide, mollusk, mass spectroscopy $]$
\end{abstract}

FMRFamide is a member of a large family of structurally related neuropeptides that have been isolated from species spanning almost all phyla of the animal kingdom (reviewed by Greenberg and Price, 1992). Most is known about the function of FMRFamide in mollusks. It has been shown to have cardioexcitatory effects in a number of species (e.g., Price and Greenberg, 1977; Buckett et al., 1990) as well as activity on other peripheral muscles (e.g., Cottrell et al., 1983; Weiss et al., 1984). Central neuronal actions by this peptide are also well known in mollusks (Abrams et al., 1984; Cottrell and Davis, 1987). The cloning of DNA sequences that encode FMRFamide and related peptides from a number of invertebrate organisms has shown that these peptides are often highly repeated within a protein precursor and are found together with a number of novel peptides (Aplysia, Schaefer et al., 1985; Drosophila, Nambu et al., 1988; Schneider and Taghert, 1988; Lymnaea stagnalis, Linacre et al., 1990; Saunders et al., 1991; Calliactis, Darmer et al., 1991; Helix, Lutz et al., 1992; Caenorhabditis elegans, Rosoff et al., 1992).

In Lymnaea, the exon encoding the tetrapeptide members of the family FMRFamide/FLRFamide is expressed in approximately 280 cells in the CNS, including the very well-characterized pair of $E_{\text {he }}$ (Egp heart excitatory) motoneurons. This is expected, as the peptides probably act as transmitters in this

\footnotetext{
Received Mar. 22, 1994; revised Apr. 22, 1994; accepted Apr. 27, 1994.

This work was supported by a grant from the SERC. Thanks are also due to Annie Bacon for the preparation of the manuscript, and Colin Atherton for help with the photography.

Correspondence should be addressed to Elaine Kellett, Sussex Centre for Neuroscience, School of Biological Sciences, University of Sussex, Brighton, BN1 9QG, East Sussex, UK.
}

Copyright $(1994$ Society for Neuroscience $0270-6474 / 94 / 146564-07 \$ 05.00 / 0$ system (Buckett et al., 1990; Brezden et al., 1991). As a consequence of alternative RNA splicing, a second exon encodes a class of N-terminally extended peptides, predominantly GDP/ SDPFLRFamide, which are expressed in approximately 57 cells (Bright et al., 1993), including a cardiorespiratory cell, the visceral white interneuron (VWI) (Skingsley et al., 1993). To some extent, peptides encoded by this exon can mimic aspects of the action of the VWI but cannot explain all its actions. For instance, the inhibitory effects of the VWI on its postsynaptic cells can be satisfactorily mimicked by GDPFLRFamide, but this does not explain the excitatory responses on other neurons (Skingsley et al., 1993). The possibility arises that the VWI therefore contains other peptides (or other transmitters) that may be encoded on separate exons within the same gene. Recently an FMRFamide-like heptapeptide SKPYMRFamide has been characterized biochemically in Lymnaea (de With et al., 1992) but has not been identified within the already described exons of the FMRFamide gene. To obtain a complete analysis of neuropeptide coding in the FMRFamide gene, we have used a combination of cDNA cloning and genomic sequencing to determine whether further neuropeptide encoding exons exist within the FMRFamide gene.

We describe the isolation, for the first time, of a cDNA encoding the GDP/SDPFLRFamide peptides and show that this cDNA encodes two further exons not previously described, making a total of at least five exons within the FMRFamide locus of Lymnaea. This cDNA encodes the previously unknown peptides SSFPRYamide and HDYMRFamide as well as SKPYMRFamide and a potential tetrabasic neuropeptide precursor cleavage site. It is likely that these sequences now complete the description of all the open reading frames and potential peptides encoded within the Lymnaea FMRFamide gene.

\section{Materials and Methods}

Molecular biological techniques. Standard molecular biological techniques were performed according to Sambrook et al. (1989).

Construction of oligonucleotides. The oligonucleotides were constructed on an Applied Biosystems 381A DNA synthesizer according to the manufacturer's instructions. The sequences of the oligonucleotides were $\left(5^{\prime}\right.$ to $\left.3^{\prime}\right)$ Primer 17 (P17), AAACAGCAAGTGGCTACGGACGACA (sense, nucleotides 5446-5470 of genomic sequence M87479); Primer 19 (P19), ATTACATGCGTTTCGGGCGCACTTC (sense, nucleotides 1202-1226 of pC2); Primer 20 (P20), CTCGGACGCGGACGCCTCTCTCTCGT (antisense, 971-947 of pC2); Primer 21 (P21), GAAGTGCGCCCGAAACGCATGTAAT (antisense, 1226-1202 of pC2); and SP3, CATCAAATGGCTGACCTGTGTCATGGC (sense, 248-275 of pC2). The $\lambda \mathrm{gt} 10$ forward and reverse primers were as in Saunders et al. (1992).

Isolation of a cDNA clone, $p C 2$. A $\lambda \mathrm{gt} 10 \mathrm{cDNA}$ library, constructed from the CNS of Lymnaea stagnalis, was screened using the synthetic oligonucleotide Primer 17. This was labeled with $\gamma^{32}$ P-ATP (Amer- 
sham, UK) and hybridizations performed under the following conditions: $6 \times$ SSC, $5 \times$ Denhardt's solution, $6.5 \%$ PEG 8000 (polyethylene glycol), and $0.5 \%$ SDS at $65^{\circ}$. In total, 40,000 pfu of the amplified library were screened. Duplicate lifts were taken and positively hybridizing plaques isolated. This was repeated until single plaques could be selected. DNA was isolated from the phage and digested with EcoRI to release the insert, which was then subcloned into pUC19.

Screening of a genomic library. An EMBL3 clone (from an EMBL3 partial Sau3A library, A. B. Smit, Amsterdam) containing an insert of approximately $20 \mathrm{~kb}$ and encoding both the hepta- and tetrapeptide coding sequences was screened using oligonucleotides P19 and P20 (labeled with $\gamma^{-32}$ P-ATP using T4 polynucleotide kinase). Positively hybridizing EcoRI fragments were subcloned into pUC19 for DNA sequencing.

Nucleotide sequence analysis. Using double-stranded DNA the subclones were sequenced in both orientations. The sequencing was performed using $\alpha^{-35} \mathrm{~S}$-dATP (Amersham, UK) and Sequenase 2.0 kits (U.S. Biochemicals, UK). The reactions were then separated on a $7 \mathbf{~}$ urea, $6 \%$ polyacrylamide gel. The resulting data were analyzed using the DNAstar (DNAstar Ltd., UK) package of programs.

Mass spectroscopy. The right internal parietal nerve was dissected and analyzed by mass spectroscopy exactly as described previously (Jiménez et al. 1994). A Finnigan MAT Vision 2000 laser desorbtion time-offlight mass spectrometer was used in conjunction with a pulsed $\mathrm{N}_{2}$ laser $(337 \mathrm{~nm}$; pulse width, $3 \mathrm{nsec})$ to irradiate $\left(10^{6}\right.$ to $\left.10^{7} \mathrm{~W} / \mathrm{cm}^{2}\right)$ the sample. After initial external calibration, the spectra were calibrated internally on previously identified peaks. Forty spectra were accumulated, and the mass accuracy of the instrument was $0.1 \%$.

Physiology. Neuropeptides SDPFLRFamide and SKPYMRFamide were applied to the surface of identified neurons via pressure pipettes while recording the responses using intracellular microelectrodes. Methods were the same as Skingsley et al. (1993). Isolated Lymnaea brains were continuously perfused with HEPES-buffered saline (Benjamin and Winlow, 1981) during pharmacological application of neuropeptides. Concentrations of peptide in the pipette were between $10^{-3}$ and $10^{-4}$ $\mathrm{M}$, but the final concentration of peptide reaching the receptors was likely to be $1-2$ orders of magnitude lower than this. Intervals of at least $10 \mathrm{~min}$ with continuous perfusion of saline occurred between successive applications of agonists.

\section{Results}

\section{Isolation of heptapeptide $c D N A$ clones}

It had previously becn shown that the tetrapeptide FMRFamide (Linacre et al., 1990) and the heptapeptides GDP/SDPFLRFamide (Saunders et al., 1991) were encoded by separate exons and that both exons are spliced onto a common 5' exon that encodes a hydrophobic leader sequence (Saunders et al., 1992). The heptapeptide cDNA sequence was not complete as a PCR product containing only the $5^{\prime}$ end of the cDNA had been isolated and sequenced. A cDNA $\lambda \mathrm{gl} 10$ library was therefore screened for clones that extended the sequences of the heptapeptide transcript $3^{\prime}$. Positively hybridizing clones were then picked, analyzed, and sequenced. One clone, pC2 (Fig. 1), when translated, was found to contain an open reading frame encoding the common hydrophobic leader sequence, and the contiguously encoded heptapeptides GDP/SDPFLRFamide and their variants. The cDNA sequence then diverged from the genomic heptapeptide coding sequence at the previously postulated $5^{\prime}$ consensus splice site (Saunders et al., 1991) and was extended 3' by $536 \mathrm{bp}$. The new sequence was found to encode two further FMRFamide-like peptides and a novel unrelated hexapeptide in addition to the previously described EFFPLamide, GDP/ SDPFLRFamide, and related peptides. These are SKPYMRFamide, HDYMRFamide, and SSFPRYamide (Fig. 2A). Each putative peptide has a $C$-terminal glycine necessary for amidation and each is bounded by single basic amino acids that are thought to be necessary for processing from the precursor. A similar tetrabasic cleavage site to that described in the tetrapeptide precursor (Fig. $2 B$ ) is also present in the heptapeptide

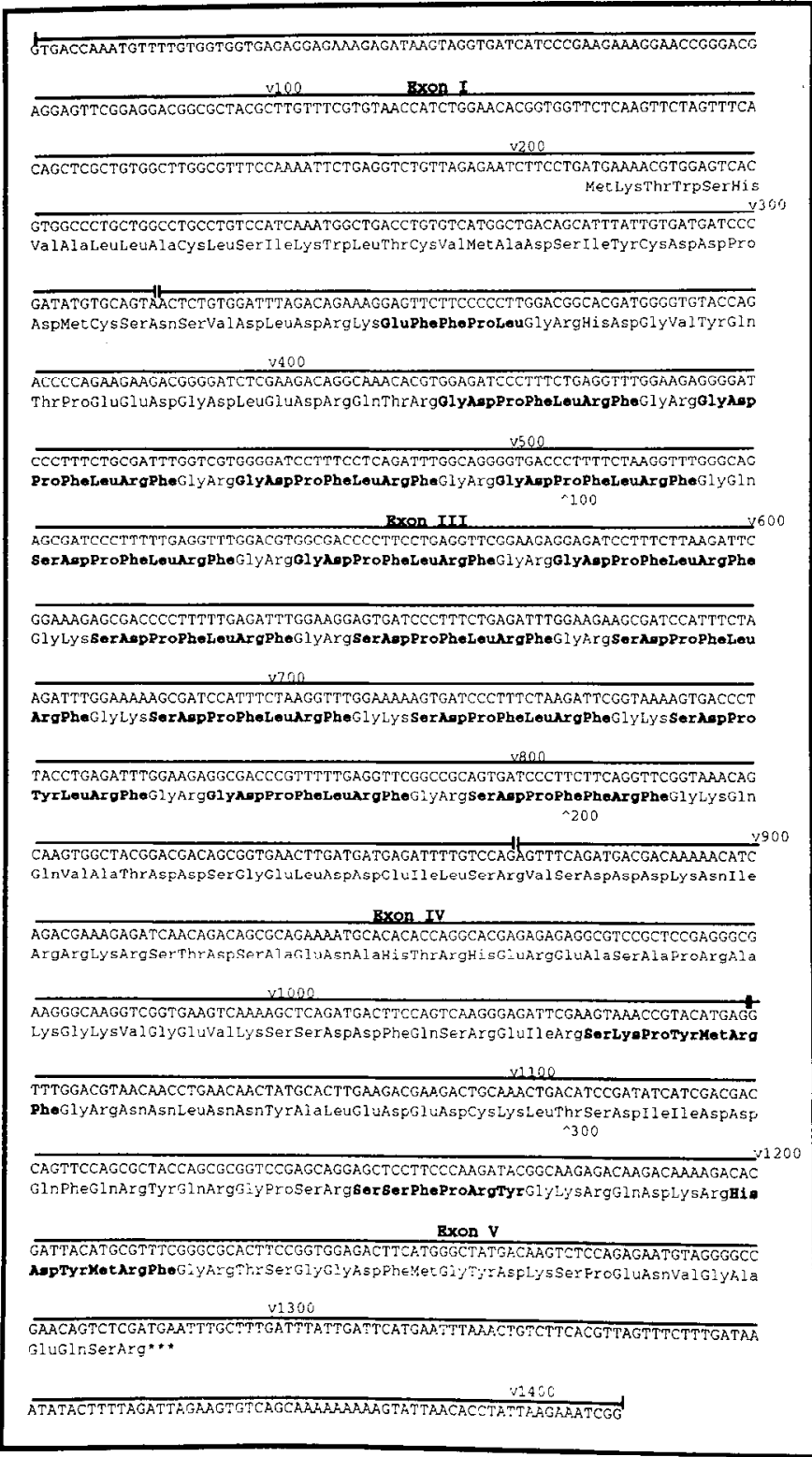

Figure 1. The complete nucleotide sequence of the cDNA clone $\mathrm{pC} 2$, which contains heptapeptide encoding sequences. The predicted amino acid sequence of the protein precursor is shown below the nucleotide sequence. Those amino acids in boldface indicate the peptides that could be processed from the protein precursor. Numbers above refer to the nucleotide sequence and numbers below to the amino acid sequence. The lines above the nucleotide sequence indicate the exons from which the cDNA was derived.

precursor, and in both cases the four basic amino acids are followed by serine and threonine.

The first stop codon (TGA) in the heptapeptide cDNA is followed by multiple stop codons in all three reading frames. Analysis of the sequence indicates that there are several putative polyA addition sites (consensus AAUAAA), but the presence of additional nucleotides after these sites and no evidence for a polyA tail in the transcript suggest that these sites are not used.

\section{Isolation of tetrapeptide cDNA clones}

It had previously been shown that the first stop codon in the tetrapeptide open reading frame is followed by multiple stop codons in all reading frames. Though there are putative polyA 


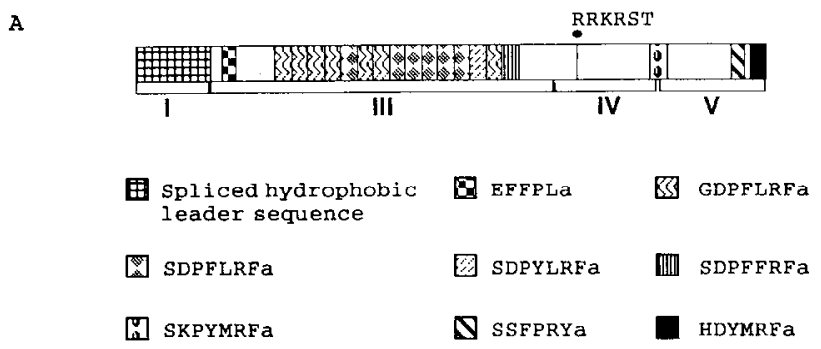

B

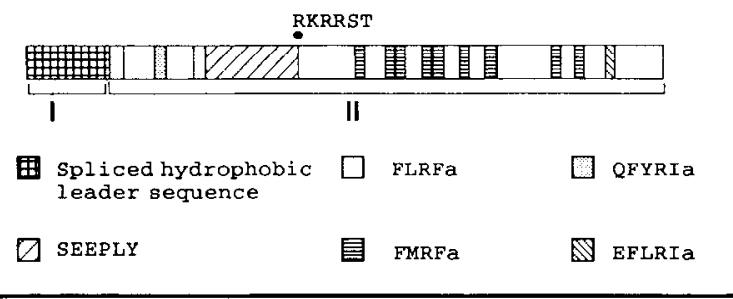

Figure 2. $A$, The predicted protein precursor encoded by $\mathrm{pC} 2$ showing the potential peptides contained within the precursor. Each peptide finishes in a C-terminal glycine and is separated from its neighbor by single basic amino acids. $B$, Shows for comparison the precursor protein encoded by the tetrapeptide mRNA. A tetrabasic cleavage site can be seen in both precursors and is followed by a conserved serine and threonine.

addition sites in the untranslated $3^{\prime}$ region, they do not appear to be used since there is no evidence of a polyA tail in the cDNAs so far analyzed. Further screening and polymerase chain reactions (PCR) to extend the FMRFamide transcript $3^{\prime}$ failed to identify a polyA tail.

\section{Attempted isolation of other spliced transcripts}

As the hydrophobic leader sequence is spliced onto both the tetra- and heptapeptide exons (Saunders et al., 1992), the possibility exists that this same sequence could also be spliced directly onto further exons. To investigate this, PCR was performed as described previously in Saunders et al. (1992) on lysates of the cDNA library with primers specific for the hydrophobic leader sequence and $\lambda \mathrm{gt} 10$, as illustrated in Figure $3 A$. Amplification, cloning, and sequencing (Fig. $3 B$ ) of the PCR products gave, in addition to the tetrapeptide and heptapeptide exons, many products that contained stop codons in all three reading frames. Only one continued as an open reading frame, but it did not encode any additional peptides. This suggests that there are no additional major transcripts other than the two described here.

\section{Analysis of genomic clones}

By analyzing a $\lambda E M B L 3$ recombinant clone it had already been established that the tetra- and heptapeptides are encoded by exons located on separate EcoRI fragments of $4.1 \mathrm{~kb}$ and 3.4 kb, respectively (Linacre et al., 1990; Saunders et al., 1991). Detailed restriction and sequence analysis has shown that the tetrapeptide exon is $1170 \mathrm{bp}$ in length and is separated from the heptapeptide exon of $672 \mathrm{bp}$, by an intron of $2.9 \mathrm{~kb}$ (GenBank accession no. M87479). The question arose as to whether the novel sequences in the $\mathrm{pC} 2 \mathrm{cDNA}$ are encoded by further exons. The $\lambda E M B L 3$ genomic clone was screened using synthetic oli- gonucleotides P20 and P19 (Materials and Methods), whose sequence was derived from the 3 ' end of the newly described pC2 cDNA sequence. Southern blot analysis of the genomic clone digested with EcoRI and probed with oligonucleotides P20 and P19 showed that the oligonucleotides hybridized to separate EcoRI fragments that were distinct from the EcoRI fragments encoding the tetra- and heptapeptide exons. The $5^{\prime}$ oligonucleotide P20 hybridized to an EcoRI fragment of $1.6 \mathrm{~kb}$, whereas the 3' oligonucleotide P19 hybridized to an EcoRI fragment of $4.0 \mathrm{~kb}$. The finding that the 3 ' portion of the new $\mathrm{cDNA}, \mathrm{pC2}$, hybridizcd to two diffcrent EcoRI fragments suggested that $\mathrm{pC} 2$ cDNA sequence was made up of at least a further two exons. By detailed restriction mapping, Southern blotting, and then subcloning and sequencing the EcoRI fragments, we were able to establish a genomic map with respect to the organization of the exons, introns, and the splice sites by comparing the genomic and cDNA sequence data (Fig. 4). One new exon (IV) is $173 \mathrm{bp}$ in length, encodes a tetrabasic cleavage sequence, and is separated from the exon encoding the heptapeptides GDP/ SDPFLRFamide by an intron of approximately $2.1 \mathrm{~kb}$. 'The other exon of 363 bp encodes the peptides SSFPRYamide and HDYMRFamide. This is separated from the preceding exon by an intron of approximately $3.5 \mathrm{~kb}$. Interestingly, the third peptide SKPYMRFamide is encoded by a sequence that is formed by the splice junction between the two newly described exons.

Comparisons of the donor and acceptor splice sites with the vertcbrate splicc sitc consensus sequences (Fig. 5) indicate that, in general, the $5^{\prime}$ donor splice sites show a high degree of sequence similarity with their vertebrate counterparts. In the two cases where determined (exons III and IV), there is a homology of at least six of nine nucleotides that fit the consensus splice site, and in both cases, this includes the highly conserved AG/ GTAA. The mammalian $3^{\prime}$ acceptor splice consensus sequence is $\mathrm{TAG} / \mathrm{G}$, the $\mathrm{AG} /$ is conserved in each exon at the $3^{\prime}$ acceptor splice sites, and the regions upstream of the splice sites are pyrimidine rich. However, it appears (from the cDNA data) that the exon I 5' donor site differs from the mammalian consensus.

\section{Mass determination of novel peptides}

In an attempt to identify the neuropeptides encoded in the $\mathrm{pC} 2$ cDNA, made up of exons I, III, IV, and V, a section of the internal right parietal nerve was analyzed by mass spectroscopy. Figurc $6 A$ shows the presence of two major peaks with molecular masses of 850.6 and 880.7 . These masses correspond to those expected for the peptides GDPFLRFamide and SDPFLRFamide, encoded seven and six times, respectively. The signal intensity reflects the relative number of peptides encoded. Two other predicted peptides can be assigned to the spectrum, SDPYLRFamide (896.4) and SKPYMRFamide (927.5). The peak heights are equivalent and are consistent with each peptide being represented only once in the precursor cDNA. The other peaks could not be assigned to known peptides, nor was the predicted peptide HDYMRFamide (867) visible, although a consistent peak of 863.4 was observed.

\section{Comparison of pharmacological effects of SDPFLRFamide and SKPYMRFamide}

The characterization of these peptides by protein sequencing (Ebberink et al., 1987; de With et al., 1992), and mass spcctroscopy shown here, led to pharmacological experiments that compared the responses of the two peptides on identified central neurons of Lymnaea. The postsynaptic cells of the VWI were 


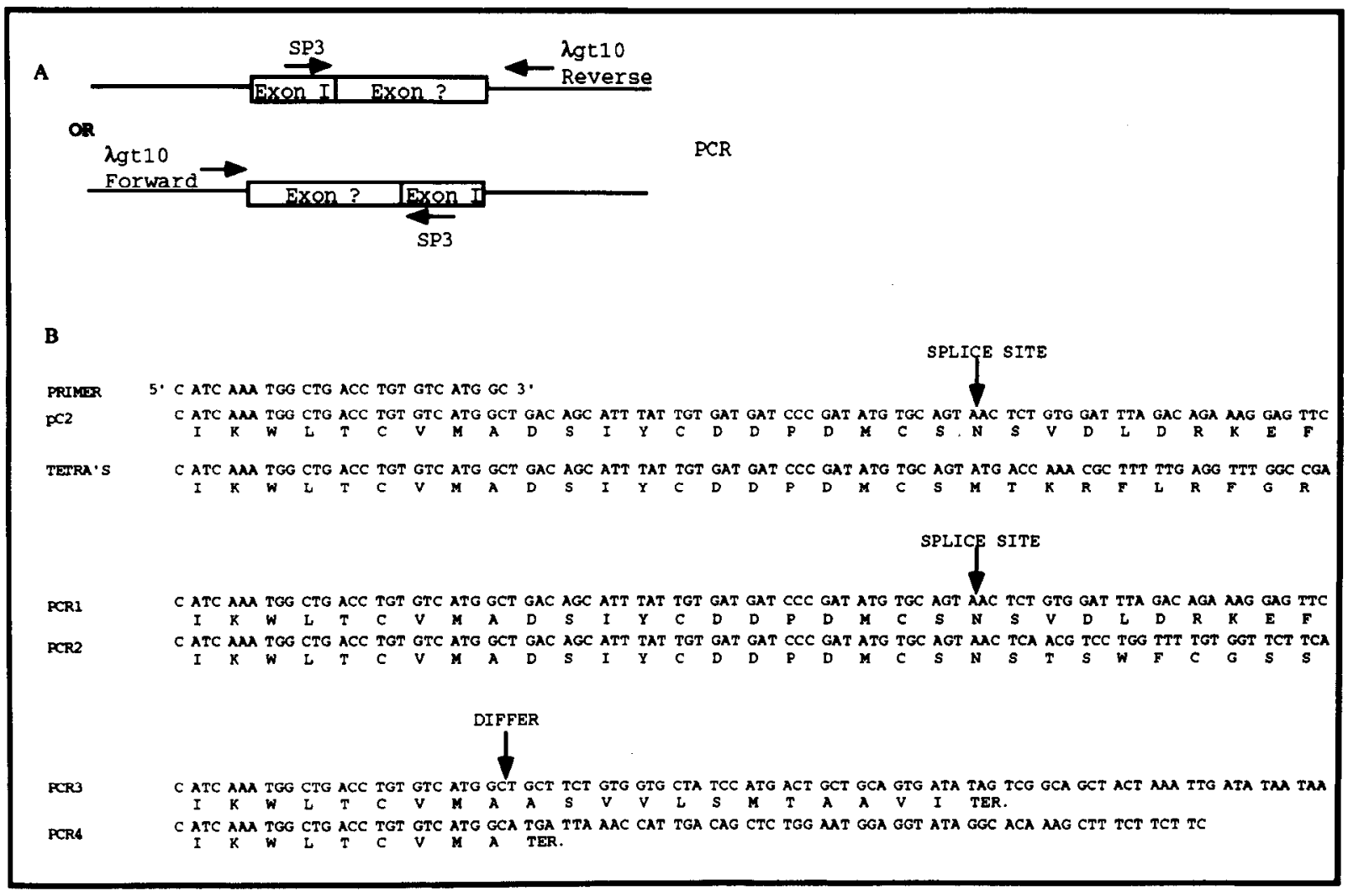

Figure 3. Strategy for the isolation of further cDNAs containing exon I. $A$, The possible orientations of exon I containing cDNAs relative to the $\lambda \mathrm{gt} 10$ cloning arms as used in PCR. The arrows indicate the direction in which the primers were used (either $\lambda \mathrm{gt} 10$ forward or reverse, together with the exon I-specific SP3). $B$, Position of the primer (SP3) relative to the tetra- and heptapeptide $(p C 2)$ encoding cDNA sequences. Four PCR products are shown: $P C R 1$ is identical to $p C 2 ; P C R 2$ differs from $p C 2$ at the splice site and maintains an open reading frame for at least 39 amino acids (not shown). Products $P C R 3$ and $P C R 4$ diverge immediately after the primer.

used, as these are the targets of the N-terminally extended peptides (heptapeptides, hexapeptides) encoded on exons III-V of the FMRFamide gene (Bright et al., 1993; Skingsley et al., 1993). As was found previously, SDPFLRFamide inhibited neuronal firing (e.g., Egp cell of Fig. 6B). However, SKPYFMRFamide often excited the same cells (Fig. 6C) and therefore more closely mimicked the VWI's synaptic effect on the Egp cells, which was also excitatory (Benjamin et al., 1988; Skingsley et al., 1993). This suggested that closely related peptides can have the opposite effects on the same neuron, presumably by acting on different receptors.

\section{Discussion}

\section{Organization of the FMRFamide locus}

The Lymnaea FMRFamide gene as described here has been found to consist of at least five exons that are alternatively spliced to produce two different mRNAs. One mRNA encodes for the tetrapeptides (FLRF/FMRFamide), whereas the other encodes for the heptapeptides (SDP/GDPFLRFamide) and other novel peptides (summarized in Fig. 7). There is no evidence to suggest the presence of a single message encoding both tetraand heptapeptides from in situ hybridization experiments using exon- and intron-specific probes (N. Santama, personal communication), nor have cDNAs characterized in this series of experiments indicated a single transcript containing both the tetra- and heptapeptide exons.

In both the tetra- and heptapeptide cDNAs the open reading frames terminate in stop codons, which are followed by multiple stop codons in all reading frames, indicating the completion of the coding sequence. Potential polyA addition sites that agree well with the corresponding consensus site (AAUAAA) have been identified in the $3^{\prime}$ untranslated regions of the cDNA clones for both types of mRNA. They do not appear to be used, however, as no cDNA clone yet isolated terminates in a polyA tail. Such a lack of a polyA tail could point to the presence of other untranslated exons that are spliced to these cDNAs. Further experiments using PCR and library screening have failed to identify any such sequences or polyA tails.

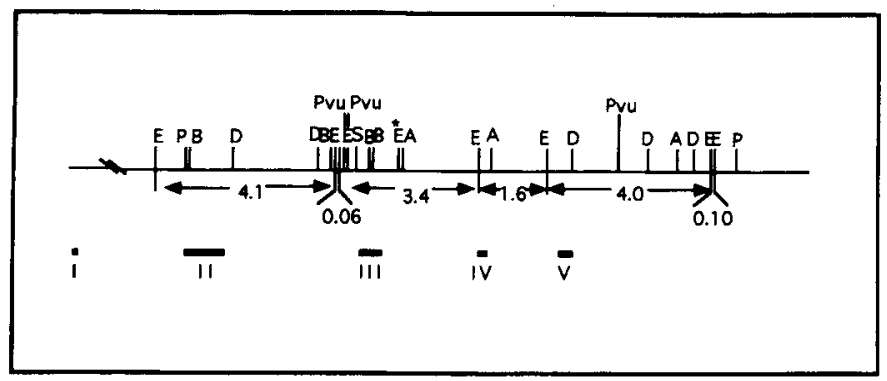

Figure 4. The genomic organization of the FMRFamide locus as determined by DNA sequencing, restriction mapping, and Southern hybridization ( $S$, SalI; $E$, EcoRI; $B$, BamHI; $P$, PstI; $D$, DraI; Pvu, PvuII; $A$, AccI; $E^{*}$, a polymorphic EcoRI site. Exons are depicted by solid lines $(I-V)$. The first exon encodes the hydrophobic leader sequence, exon II (the tetrapeptides), and exons III, IV, and V (the heptapeptides and other peptides encoded by pC2). Distances between EcoRI sites are indicated. 


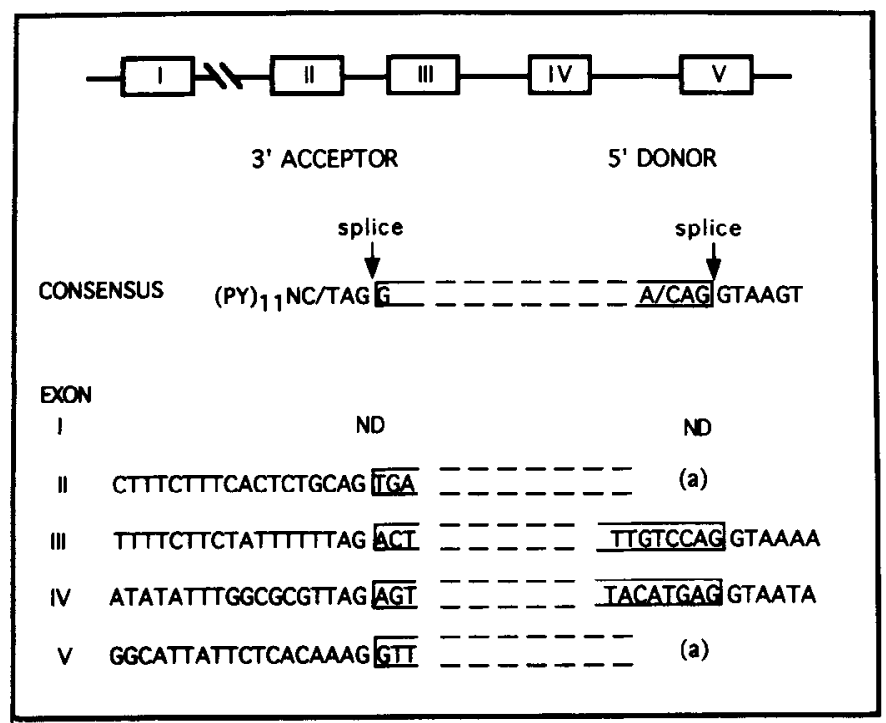

Figure 5. Comparison of the $5^{\prime}$ and $3^{\prime}$ boundaries of the exons of the FMRFamide gene with the vertebrate consensus splice site sequences (Padgett et al., 1986). The FMRFamide exon splice sites were determined by comparison of cDNA and genomic sequences $(N D$, not determined). $a$ indicates that the cDNA at genomic sequences are identical (i.e., no splicing) but contain stop codons at predicted polyA addition sequences.

One PCR product did, however, reveal the presence of another potential exon (Fig. 3). Sequence data indicated the primer had annealed correctly and the sequence matched that of exon I (hydrophobic leader sequence) but then diverged from both exon II and exon III sequences at the splice site. Only a small amount of further sequence data has been determined for this potential exon; however, there is sufficient sequence to enable the construction of an oligonucleotide probe for the use in in situ hybridization experiments. If the probe is found to hybridize to mRNA in the cytoplasm then further attempts to isolate a cDNA clone containing a larger fragment of this putative exon will be performed.

\section{Comparison of the FMRFamide locus in Lymnaea and other organisms}

Genes encoding FMRFamide and FMRFamide-related peptides have been identified in other invertebrate species. Comparisons of these genes with the Iymnaea gene has identified certain similarities. In Aplysia, five cDNAs encoding multiple copies of FMRFamide have been sequenced, and it was suggested by Taussig and Scheller (1986) that the variations displayed by the clones may be due to alternate RNA splicing. Little is known, however, regarding the genomic sequence and hence the organization of the gene.

Comparisons may also be drawn between Helix and Lymnaea. It has been shown that Helix produces two mRNAs, both of which are incomplete at the $3^{\prime}$ termini. One encodes the tetrapeptides FMRFamide and FLRFamide, and the other encodes the heptapeptides (Lutz et al., 1992). Although this would appear to be similar to Lymnaea, no evidence for alternate splicing has yet been demonstrated. Of the remaining genes for which the exon organization is known, Drosophila has two cxons, one being noncoding, and $C$. elegans, five exons (Chin et al., 1990; Schneider and Taghert 1990; Rosoff et al., 1992). Thus, in terms of genomic organization, Lymnaea most resem-
A

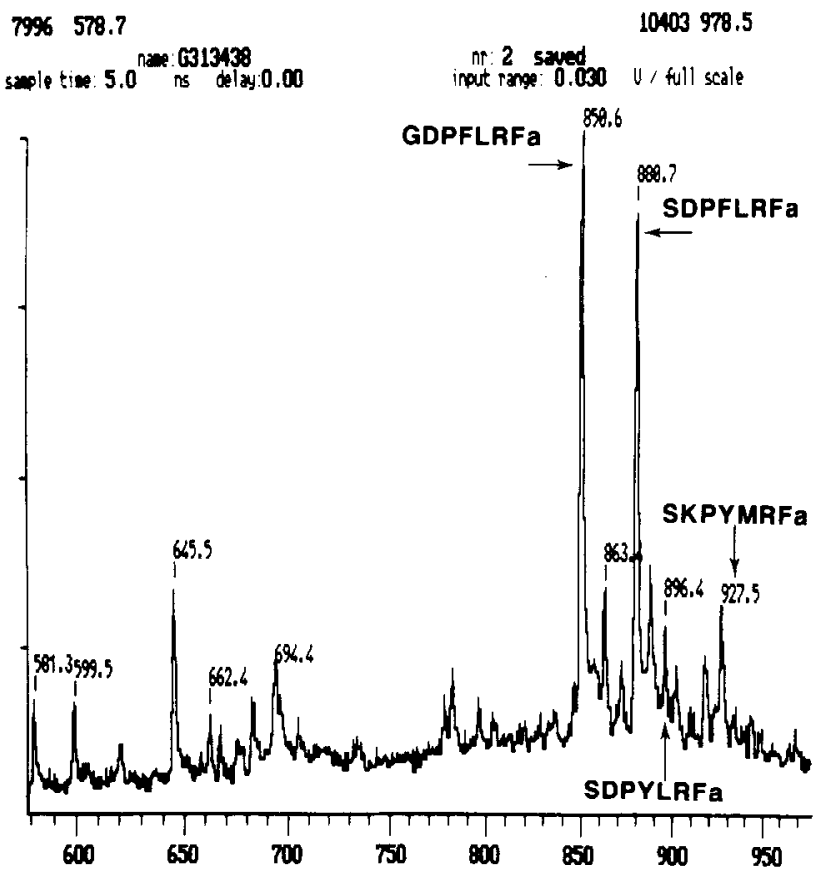

B

SDPFLRFa

10-4 M Pipette Conc
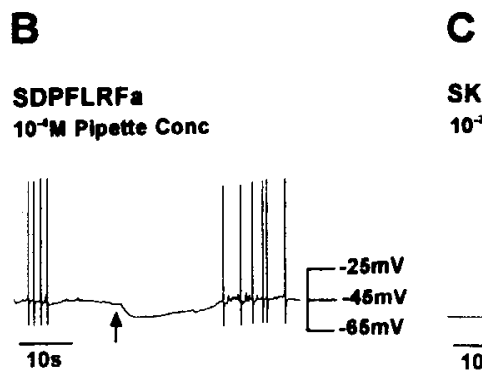

SKPYMRF

$10^{-4}$ M Pipette Conc

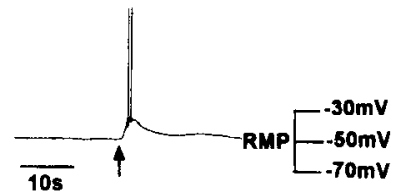

Figure 6. Mass spectroscopic analysis of the right internal parieta nerve and physiological activity of SKPYMRFamide. $A$, Approximately $0.5 \mathrm{~mm}$ of nerve was analyzed as described in Materials and Methods. Peaks corresponding to predicted peptides are indicated. A $1 \mathrm{sec}$ pressure pulse of SDPFLRFamide $(B)$ hyperpolarized an Egp cell, whereas SKPYMRFamide $(C)$ produced the opposite depolarizing response leading to spiking, on the same cell. The cell in $B$ was depolarized slightly, whereas it was at resting membrane potential $(R M P)$ in $C$.

bles $C$. elegans, though in $C$. elegans the introns are very short. The FMRFamide encoding genes in Drosophila and C. elegans differ from those of Lymnaea in that both encode multiple copies of N-terminally extended versions of the peptide but no copies of the tetrapeptides, as found in mollusks.

\section{Peptides encoded by the FMRFamide locus and their physiological actions}

The overall structure of the protein precursors and the peptides encoded by each mRNA can be deduced from the cDNA sequences. In Lymnaea, the tetrapeptide precursor encodes multiple copies of FMRFamide that are delineated by dibasic amino acids at the $\mathrm{N}$-terminus. The heptapeptides are arranged differently, being divided by a single basic amino acids. The exceptions in the $\mathrm{pC} 2$ cDNA are EFFPLamide and HDYMRFamide encoded at the extreme $\mathrm{N}$ and $\mathrm{C}$ termini; these have $\mathrm{N}$-terminal dibasic amino acids. In Lymnaea, both precursor proteins contain a tetrabasic amino acid sequence, RKRR (te- 


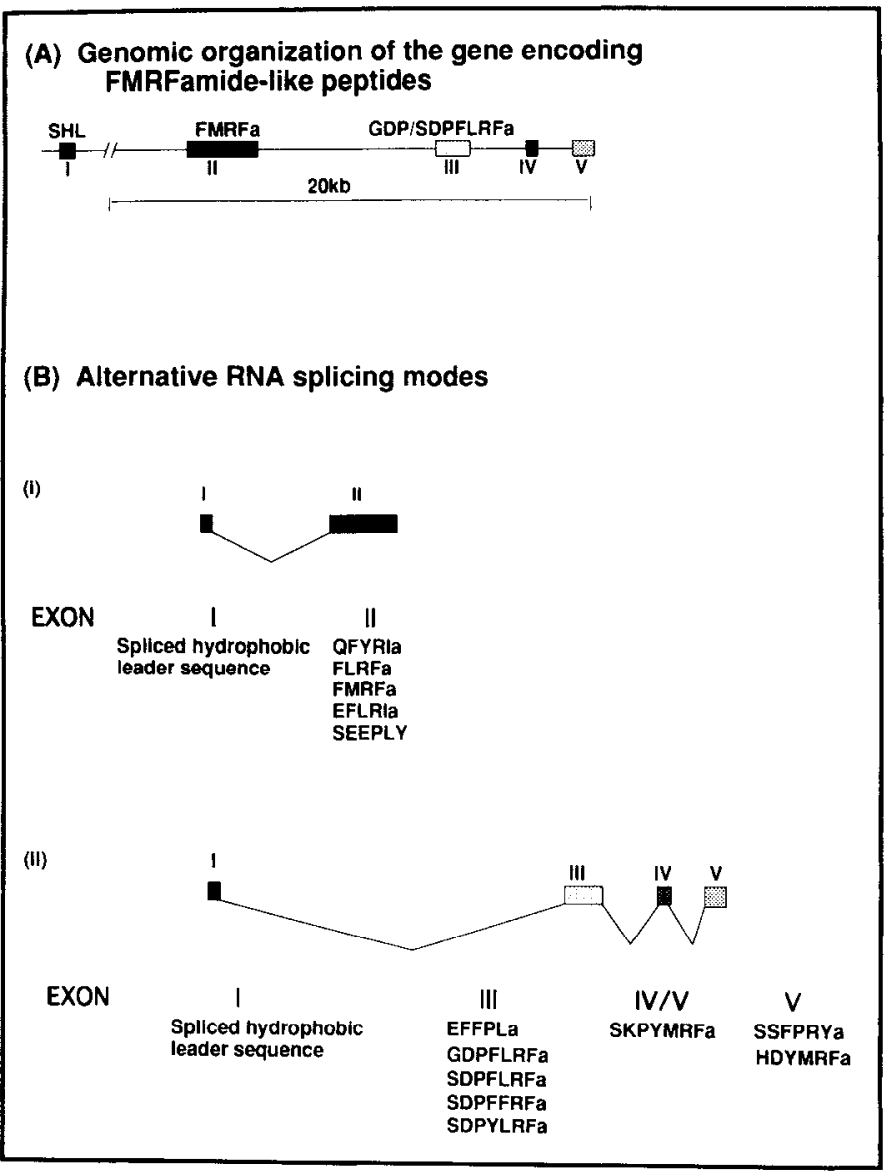

Figure 7. Summary diagram of the genomic organization of the FMRFamide locus, the alternatively spliced mRNAs, and the potential peptides derived from these precursors.

trapeptides), and, as shown here, RRKR (heptapeptides) followed by conserved serine (S) and threonine (T) amino acids. These conform to the consensus sequence $[\mathrm{RX}(\mathrm{K} / \mathrm{R}) \mathrm{R}]$ for cleavage by furin-like enzymes that are involved in the initial rapid cleavage of protein precursors and have been found in genes encoding other neuropeptides, for example, egg-laying hormone (ELH) in Aplysia (Nambu and Scheller, 1986; Newcomb et al., 1988). A peptide predicted from the DNA sequence spanning the region between the FLRFamide cleavage and tetrabasic cleavage sites has recently been isolated (Santama et al., 1993) and may have a significant modulatory role on the tetrapeptides encoded by the same exon. By analogy we would predict the existence of a peptide spanning exon III and IV, the $\mathrm{N}$-terminal amino acid being generated by the cleavage of lysine after the last SDPFFRFamide peptide and at the C-terminal by the cleavage of the RRKR sequence. In the ELH prohormone of Aplysia it has been shown that after the initial cleavage at the tetrabasic cleavage site, the $\mathrm{N}$-terminal and $\mathrm{C}$-terminal peptides are differentially packaged into vesicles (Fisher et al., 1988; Newcomb et al., 1988). This raises the possibility that the tetrabasic cleavage sites in the tetrapeptide and heptapeptide precursors are playing a role in separating peptides that have different physiological actions to different classes of secretory vesicle. The absence of HDYMRFamidc and SSFPRYamide from the mass spectrum may indicate that differential processing and sorting is occurring at this stage, or possibly later stages; indeed, preliminary independent data suggest that at least one peptide
(SDPFFRFamide) is not produced. However, more trivial explanations cannot be ruled out.

As the heptapeptide and tetrapeptide exons are differentially expressed, for example, in the $E_{\text {ne }}$ cells (Bright et al., 1993; Santama et al., 1993) and the VWI (Skingsley et al., 1993), these are likely to be of some physiological consequence. The target for the $E_{\mathrm{he}}$ cell (the heart) would be expected to respond more specifically to the tetrapeptides, for example, FMRFamide rather than the heptapeptides, and indeed this is the case (Buckett et al., 1990). Conversely, follower neurons of the VWI, which expresses cxons III-V, the heptapeptides, would be expected to respond more selectively to these peptides than the tetrapeptides. Again, in the case of the inhibitory effects of GDPFLRFamide compared with FMRFamide, this has been shown to be true. In view of the existence of exons IV and V, then it is tempting to argue that each of these exons may encode a class of peptide with further types of physiological effects. As shown in Figure 2, exon IV encodes the tetrabasic cleavage sequence as well as the $\mathrm{N}$-terminal part of the heptapeptide SKPYMRFamide. Exon V encodes the C-terminal portion of SKPYMRFamide as well as the six amino acid peptides SSFPRYamide and HDYMRFamide. It was important to determine whether these peptides differ in their physiological actions relative to SDPFLRFamide and the other heptapeptides. Preliminary physiological studies showed this to be the case. While SDPFLRFamide inhibited central neurons, the newly characterized SKPYMRFamide had the opposite excitatory effects. This could more fully account for the effects of the VWI on its follower cells, which are often excitatory (Skingsley et al., 1993). The generality of this observation, that different peptides encoded within the same precursor may have contrasting effects on the same target cells, will be important to establish.

\section{References}

Abrams TW, Castellucci VF, Camardo JS, Kandel ER, Lloyd PE (1984) Two endogenous neuropeptides modulate the gill and siphon withdrawal reflex in Aplysia by presynaptic facilitation involving cAMPdependent closure of a serotonin-sensitive potassium channel. Proc Natl Acad Sci USA 81:7956-7960.

Benjamin PR, Winlow W (1981) The distribution of three wide-acting synaptic inputs to identified neurons in the isolated brain of Lymnaea stagnalis. Comp Biochem Physiol [A] 70:293-307.

Benjamin PR, Buckett KJ, Peters M (1988) Neurons containing FMRFamide-like peptides in the model invertebrate system, Lymnaea. Symp Biol Hung 3:247-259.

Brezden BL, Benjamin PR, Gardner DR (1991) The peptide FMRFamide activates a divalent cation-conducting channel in heart muscle cells of the snail Lymnaea stagnalis. J Physiol (Lond) 443: $727-738$.

Bright K, Kellett E, Saunders SE, Brierley M, Burke JF, Benjamin PR (1993) Mutually exclusive expression of alternatively spliced FMRFamide transcripts in identifed neuronal systems of the snail Lymnaea. J Neurosci 13:2719-2729.

Buckett KJ, Dockray GJ, Osborne NN, Benjamin PR (1990) Pharmacology of the myogenic heart of the pond snail Lymnaea stagnalis. J Neurophysiol 63:1413-1425.

Chin AC, Reynolds ER, Scheller RH (1990) Organization and expression of the Drosophila FMRFamide-related prohormone gene. DNA Cell Biol 9:263-271.

Cottrell GA, Davis NW (1987) Multiple receptor sites for a molluscan peptide (FMRFamide) and related peptides of Helix. J Physiol (Lond) 382:51-68.

Cottrell GA, Schot LPC, Dockray GJ (1983) Identification and probable role of a single neuron containing the neuropeptide Helix FMRFamide. Nature 304:638-640.

Darmer D, Schmutzler C, Diekhoff D, Grimmelikhuijzen CJP (1991) Primary structure of the precursor for the sea-anemone neuropeptide 
Antho-RFamide (<Glu-Gly-Arg-Phe- $\mathrm{NH}_{2}$ ). Proc Natl Acad Sci 88: 2555-2559.

de With ND, van der Schors RC (1992) SKPYMRFamide, a novel FMRFamide-related peptide in the snail Lymnaea stagnalis. Neuroreport 3:612-614.

Ebberink RHM, Price DA, Van Loenhout H, Doble KD, Richm JP, Geraerts WPM, Greenberg MJ (1987) The brain of Lymnaea contains a family of FMRFamide-like peptides. Peptides 8:515-522.

Fisher JM, Sossin W, Newcomb R, Scheller RH (1988) Multiple neuropeptides derived from a common precursor are differentially packaged and transported. Cell 54:813-822.

Greenberg M, Price DA (1992) Relationships among the FMRFamidelike peptides. In: Progress in brain research, The peptidergic neuron (Joosse J, Buijs RM, Tilders FJH, eds), pp 92:25-37. Cambridge: Elsevier.

Jiménez CR, van Veelen PA, Li KW, Wildering WC, Geraerts WPM Tjaden VR, Van der Greef J (1994) Neuropeptide expression and processing as recorded by direct matrix-assisted laser desorbtion ionization mass spectroscopy of single neurons. J Neurochem 62:404407.

Linacre A, Kellett E, Saunders S, Bright K, Benjamin PR, Burke JF (1990) Cardioactive neuropeptide Phe-Met-Arg-Phe- $\mathrm{NH}_{2}$ (FMRFamide) and novel related peptides are encoded in multiple copies by a single gene in the snail Iymnaea stagnalis. J Neurosci $10: 412-419$

Lutz EM, MacDonald M, Hettle S, Price DA, Cottrell GA, Sommerville J (1992) Structure of cDNA clones and genomic DNA encoding FMRFamide-related peptides (FaRPs) in Helix. Mol Cell Neurosci 3:373-382.

Nambu JR, Scheller RH (1986) Egg-laying hormone genes of Aplysia: evolution of the ELH gene family. J Neurosci 6:2026-2036.

Nambu JR, Murphy-Erdosh C, Andrews PC, Feistner GJ, Scheller RH (1988) Isolation and characterization of a Drosophila neuropeptide gene. Neuron 1:55-61.

Newcomb R, Fisher JM, Scheller RH (1988) Processing of the egglaying hormone (ELH) precursor in the bag cell neurons of Aplysia. J Biol Chem 263:12514-12521.

Price DA, Greenberg MJ (1977) Structure of a molluscan cardioexcitatory neuropeptide. Science 197:670-671.
Rosoff ML, Bürglin TR, Li C (1992) Alternatively spliced transcripts of the flp-1 gene encode distinct FMRFamide-like peptides in Caenorhabditis elegans. J Neurosci 12:2356-2361.

Sambrook J, Fritsch EF, Maniatis T (1989) Molecular cloning: a laboratory manual, $2 d$ ed. Cold Spring Harbor, NY: Cold Spring Harbor Laboratory.

Santama N, Li KW, Bright KE, Yeoman M, Geraerts WPM, Benjamin PR, Burke JF (1993) Processing of the FMRFamide precursor protein in the snail Lymnaea stagnalis: characterization and neuronal localization of a novel peptide, 'SEEPLY' Eur I Neurosci 5:10031016.

Saunders SE, Bright K, Kellett E, Benjamin PR, Burke JF (1991) Neuropeptides Gly-Asp-Pro-Phe-Leu-Arg-Phe- $\mathrm{NH}_{2}$ (GDPFLRFamide)

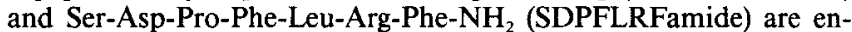
coded by an exon 3' to Phe-Met-Arg-Phe- $\mathrm{NH}_{2}$ (FMRFamide) in the snail Lymnaea stagnalis. J Neurosci 11:740-745.

Saunders SE, Kellett E, Bright K, Benjamin PR, Burke JF (1992) Cell specific alternative RNA splicing of an FMRFamide gene transcript in the brain. J Neurosci 12:1033-1039.

Schaefer M, Picciotto MR, Kreiner T, Kaldany RR, Taussig R, Scheller RH (1985) Aplysia neurons express a gene encoding multiple FMRFamide neuropeptides. Cell 41:457-467.

Schneider LE, Taghert PH (1988) Isolation and characterization of a Drosophila gene that encodes multiple neuropeptides related to PheMet-Arg-Phe- $\mathrm{NH}_{2}$ (FMRFamide). Proc Natl Acad Sci USA 85:19931997.

Schneider LE, Taghert PH (1990) Organization and expression of the Drosophila Phe-Met-Arg-Phe- $\mathrm{NH}_{2}$ neuropeptide gene. J Biol Chem 265:6890-6895.

Skingsley DR, Bright K, Santama N, van Minnen J, Brierley MJ, Burke JF, Benjamin PR (1993) A molecularly-defined cardiorespiratory interneuron expressing SDPFLRFamide/GDPFLRFamide in the snail Lymnaea: monosynaptic connections and pharmacology. J Neurophysiol 69:915-927.

Taussig R, Scheller RH (1986) The Aplysia FMRFamide gene encodes sequences related to mammalian brain peptides. DNA 5:453-461.

Weiss S, Goldberg JI, Chohan KS, Stell WK, Drummond GI, Lukowiak $\mathrm{K}$ (1984) Evidence for FMRFamide as a transmitter in the gill of Aplysia californica. J Neurosci 4:1994-2000. 